\title{
Large-Scale Micron-Order 3D Surface Correlative Imaging of Ancient Roman Concrete
}

\author{
Janille Maragh ${ }^{1}$, James C. Weaver ${ }^{2}$ and Admir Masic ${ }^{3}$ \\ 1. Department of Civil and Environmental Engineering, MIT, Cambridge, USA. \\ 2. Wyss Institute for Biologically Inspired Engineering, Harvard University, Boston, USA.
}

In recent years, great strides have been taken in the characterization of complex, heterogeneous ancient materials to gain a better understanding of their structure-function relationships. In this work, we apply a new set of high throughput characterization tools to study ancient Roman concrete, which is a particularly interesting material that shows heterogeneities and complexity across multiple scales, each of which are important for understanding its mechanics, its resilience, how it degrades, and for making informed decisions regarding its preservation.

Ancient Roman cement paste is a mixture of calcined limestone, which has been slaked with water to form calcium hydroxide, and volcanic ash. The use of ancient Roman cement in the production of mortar (mixture of cement paste and fine aggregate) and opus coementicum or Roman concrete (mixure of mortar with larger aggregate: coementa) [1] has permitted the fabrication of some of antiquity's most massive architectural marvels. The addition of pozzolana (high alkali volcanic ash, primarily consisting of amorphous aluminosilicates), native to the areas surrounding Mount Vesuvius in Campania, to the mixture resulted in a superior binding mortar [2]. This mortar produces concretes with a greater compressive strength than concrete produced using pure lime cement, due to the formation of amorphous or poorly-crystalline calcium silicate hydrate $(\mathrm{C}-\mathrm{S}-\mathrm{H})$ and calcium aluminium silicate hydrate (C-A-S-H) gel phases, which are produced in reaction layers surrounding pozzolana fragments as they react with the slaked lime [3].

Recently, SEM-EDS and Raman spectroscopy have been optimized to enable the collection of large area (cm range) micron-resolution phase maps of biological composite materials [4]. These techniques have been further augmented for use on samples with irregular surfaces. With the development of TrueSurface $^{\circledR}$ profilometry, it has become possible to pair large area Raman spectroscopy with topography measurements through the use of a piezo-driven stages to maintain confocality. SEM-EDS systems with multiple detectors have also been developed to solve the shadow artifact issue, which was formerly a problem encountered when measuring irregular surfaces with a single detector. Researchers were able to harness the strengths of these complementary augmented spectroscopy and microscopy techniques in the study of native sea urchin teeth: the elemental distribution on the sample surface was measured using SEM-EDS under vacuum, but the measurement of magnesium for native, hydrated samples was made possible via the measurement of the location of the $\mathrm{v}_{1} \mathrm{CO}_{3}{ }^{2-}$ peak using Raman spectroscopy, which does not require the sample to be under vacuum [5]. We applied these microspectroscopic techniques to study samples of ancient Roman concrete (Figure 1) to determine the phases present, and differentiate the weaker phases present on the fracture surface from the bulk composition (Figure 1). We furthermore present data collected using RISE microscopy, which integrates microscale Raman imaging and nanoscale SEM/EDS on polished samples in one unified correlative system (Figure 2) [6]. 


\section{References:}

[1] L.C. Lancaster, Concrete Vaulted Construction in Imperial Rome: Innovations in Context, 1st ed., Cambridge University Press, New York.

[2] Vitruvius., M.H. Morgan, The Ten Books on Architecture, 1st Ed. Reprinted]., Dover Publications, New York.

[3] E.S. Hodgkinson, C.R. Hughes, Geol. Soc. London, Spec. Publ. 157 (1999) p. 195.

[4] S.D. Palkovic et al, Constr. Build. Mater. 115 (2016) p. 13.

[5] A. Masic, J.C. Weaver, J. Struct. Biol. 189 (2015), p. 269.

[6] The authors would like to thank the community of Priverno and Professor Margherita Cancellieri, for their cooperation in providing access to the Privernum archaeological site, and Dieter Brommer and Dr. Steven Palkovic for their invaluable insights throughout this work through frequent and meaningful discussions.

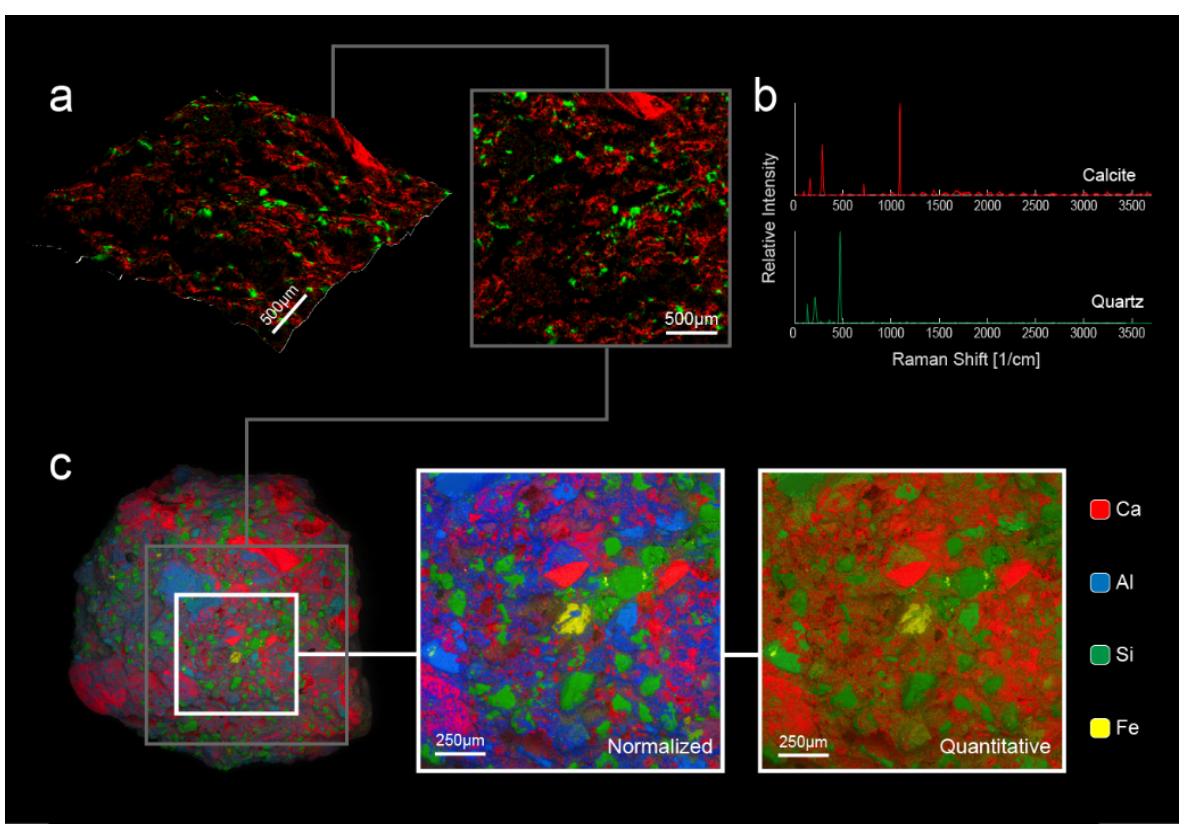

Figure 1. Raman and EDS phase maps of a fracture surface of ancient Roman concrete. (a) Raman phase map overlaid onto topography showing distribution of (b) phases detected, and (c) EDS element maps.

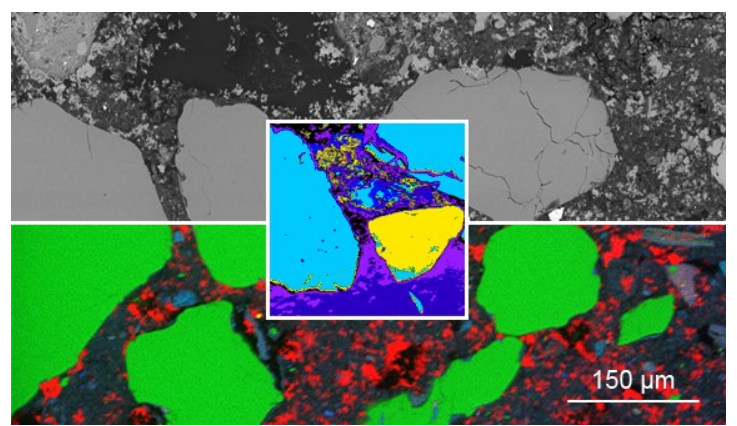

Figure 2. Correlative SEM, EDS and Raman phase mapping conducted using a combined system. Backscattered SEM image (top) and EDS element (Si, Ca, and Al) map overlaid (bottom). (Center) SEM image with Raman phase map overlaid. 